\title{
O modelo de escola que temos prepara os jovens para viverem na sociedade atual?
}

\author{
Aglaé Cecilia Toledo Porto Alves*
}

ALVES, A. C. T. P. O modelo de escola que temos prepara os jovens para viverem na sociedade atual? R. Museu Arq. Etn., 32: 41-48, 2019.

Resumo: Sociedade pós-moderna, pós-industrial, sociedade líquida, pós-humano, hiperesfera, inteligência artificial, Web 3.0, indústria 4.0, sociedade do cansaço, ambientação em Marte. Em meio a esta convulsão social, urge refletir sobre o papel da instituição escola na atualidade. Será que ela cumpre sua função primeira, a saber, preparar os jovens para inserção no mundo do trabalho e desenvolver uma consciência social? Como auxiliar as futuras gerações a enfrentar os enormes desafios que se apresentarão em um modelo social que ainda não conhecemos, num mundo no qual a única certeza é a incerteza, onde tudo que era sólido se liquefez? Será suficiente a integração das Tecnologias Digitais da Informação e Comunicação - TDIC nos currículos para que a escola possa resolver os incomensuráveis problemas que enfrenta? Morin afirma que "os homens sempre elaboram falsas concepções de si próprios, do que fazem, do que devem fazer, do mundo onde vivem”. Desta maneira, caberia à escola desvendar a ilusão e ter a coragem de praticar a parresía dos gregos que significa ter a coragem de dizer a verdade sobre si mesmo. A escola deverá ter a coragem de enxergar a si mesma, percebendo suas fragilidades. O modelo árvore, sequencial, linear, imposto ao longo dos tempos já não contempla uma sociedade rizomática, na qual há a multiplicidade dos múltiplos. O mundo jamais será igual após o advento das TDIC. A inteligência artificial e a simbiótica relação entre homem e máquina mudarão radicalmente a maneira de o humano ser, estar e perceber o mundo. Não haverá como o homem competir com a máquina. Desta maneira, não caberá à escola formar tecnocratas para o mundo do trabalho, mas resgatar aquilo que o humano tem de melhor, que é sua subjetividade, sua capacidade de sentir, sua singularidade, sua unicidade em meio à multiplicidade.

Palavras-chave: Cultura global; Hiper-realidade; Comunidades virtuais; Tecnologias digitais; Escola.

\section{Cultura Global}

A cultura global é resultante do exacerbamento da modernidade e da transfor-

(*) Secretaria de Estado da Educação de São Paulo. <aglaeportoalves@gmail.com> mação desta modernidade simples ou precoce para o atual modelo social, conhecido também como modernidade tardia ou reflexiva, pós-tradicional, pós-moderna, pós-industrial, globalizada, sociedade da informação, do conhecimento ou comunicacional, hiperesfera, ou ainda, sociedade do cansaço ou do pós-humano. 
O modelo de escola que temos prepara os jovens para viverem na sociedade atual?

R. Museu Arq. Etn., 32: 41-48, 2019.

Há uma supersaturação, capaz de se precipitar a qualquer momento, na utilização dos termos mencionados que acabaram quase se banalizando, e ainda causam desconforto, pela insistência em se repetir. Talvez a melhor maneira de definir esta tão discutida atualidade seja uma sociedade líquida, como sugere Bauman (2008), capaz de assumir infinitas formas, mas que por si não possua nenhuma.

A integração das diversas culturas, possibilitada pelas novas tecnologias digitais que desencadearam na mudança da relação espaço/tempo, permite a produção de identidades plurais e provisórias que convivem na atualidade, caracterizada pela velocidade vertiginosa, em relação ao passado, das alterações no modus vivendi.

Desta maneira, torna-se evidente a necessidade premente de mudanças estruturais em todas as instituições, especificamente na escola, que já não atende plenamente às expectativas da sociedade. Todo o sistema deverá se tornar totalmente aberto, um intervalo aberto em que nada é reduzido, nenhuma restrição é imposta, nem são determinados limites e no qual todas as direções podem tender ao infinito. Uma constante aprendizagem sem ensino, na qual todos são aprendentes, contemplando a educação formal, não formal e informal, com conexão contínua, hibridizando o local e o não local, entendido como ciberespaço.

Assim, a vida se situa e passa a ser percebida em um mundo plenamente aberto, com possibilidades de interações e conexões em todos os pontos. Como os sistemas abertos, a vida sofre influência externa e interna, flutuando entre a organização e a desorganização, na qual a desordem gera a ordem, e vice-versa.

Em consonância com o pensar de um mundo aberto, sem restrições, é direito dos jovens, habitantes deste pequeno e insignificante planeta, estabelecer contato e troca de experiências com seus pares, inclusive com aqueles que habitam em diferentes espaços, a fim de enriquecer a diversidade de olhares para o mesmo ponto, ou seja, multiplicar a unidade múltipla.

Entretanto, o enorme desafio a ser superado é o perigo da criação de uma massa humana compacta, homogênea, amorfa, displásica, insípida advinda desta cultura global, na qual não compensará despender o esforço necessário para atingir o infinito prazer de procurar o isolamento do instante único, absolutamente particular, para que esse instante possa ser vivido como uma vida plena.

A atualidade se caracteriza por uma mobilidade maior em um espaço indefinido, no qual as relações de poder não são mais pela força, mas se encontram nas vias culturais e econômicas, e os elos sociais precisam ser efetivamente construídos e não herdados do passado. $\mathrm{O}$ sistema democrático provavelmente não será suficiente para ser aplicado a essa realidade que tende a se organizar por redes assimétricas decorrentes da insegurança social e do movimento crescente da política internacional

Como o homem é um ser cultural e precisa saber-se, é um dever seu procurar entender o momento em que vive, não sendo possível ignorar as mudanças vividas, percebidas e sentidas que modificam o cotidiano, visto que o mundo pode ser a representação do ser. "Não há um sol, uma terra, mas o olho que vê o sol, uma mão que toca a terra... Ser é ser percebido" (Schopenhauer 2003:9).

A dicotomia entre o eu e o nós na sociedade atual poderá ser interpretada não como uma forma de egoísmo. $\mathrm{O}$ eu, na cultura global, poderá questionar o próprio eu e, com este movimento, haverá a ampliação da consciência para orientar a relação imbricada e não delineada do eu e do nós. O transbordamento de vários "eus" reflexivos na sociedade pode se transformar em um coletivo, em um nós, capaz de pensar e agir.

"Todo outro é um outro eu mesmo. Ele é como esse duplo que tal doente percebe sempre a seu lado, que se parece com ele como irmão, que ele jamais poderia fixar sem fazê-lo desaparecer, e que visivelmente não é senão um prolongamento externo dele mesmo, já que um pouco de atenção é suficiente para reduzi-lo. Eu e o outro somos como dois círculos quase concêntricos, e que se distinguem apenas por uma leve e misteriosa diferença. É no mais íntimo de mim que se produz a estranha articulação com o outro; o mistério de um outro não é senão o mistério de mim" (Merleau-Ponty 2002:168). 
O futuro na modernidade reflexiva é absolutamente incerto; nele o imponderável terá condições ideais para se sobressair, mas pode-se esperar o inesperado de uma maneira esperada, ou seja, preparar competências para habitar o incerto.

\section{A hiper-realidade \\ "O engano autêntico." \\ Umberto Eco}

Outra característica da cultura global é a imersão das pessoas em uma hiper-realidade, definida por Jean Baudrillard (1991) como "a simulação de algo que nunca existiu realmente”.

Bergson (2006) afirma que se as pessoas, ao invés de viverem a vida, somente sonhassem, a vida seria só uma sucessão de memórias, como uma sessão de fotografias antigas. Em contrapartida, ao negar as memórias e todas as suas consequências, as pessoas atuariam em sua existência como um autômato consciente, em meio ao conceito de presente como um recomeçar incessante.

Essa atuação seria totalmente desprovida de sentido, visto que não seria possível acessar a realidade sem as memórias, entender o momento atual, muito menos atribuir valor à ação.

Benjamin (1994) entende que na hiper-realidade a mercadoria teria um signo de valor dependente do contexto social em que estiver inserida. O objeto por si seria destituído de significado; o valor seria atribuído por alguma convenção, normalmente social, que permitisse ao não ser parecer ser. Viver na hiper-realidade significa a possibilidade de nada ser, embora simplesmente se pareça ser.

As pessoas não necessitam acessar as memórias para entender o presente, basta que atuem segundo um roteiro, de forma a fomentar a ilusão de tal maneira que convençam os outros de que sua falsidade é uma veracidade. Ao imergir nessa hiper-realidade, a definição do que é a realidade se torna cada vez mais difícil, comprometendo, muitas vezes, de forma irreversível, o questionamento sobre o que é real e o que é ilusão. É preciso um esforço intelectual e uma vontade inteira e interna para suscitar a reflexão sobre essa alteração de signos.
O consumismo é uma das consequências da hiper-realidade. As pessoas não mais adquirem bens pela sua funcionalidade ou necessidade real, mas pela imposição de uma publicidade que induz um desejo ao que não é necessário e uma garantia de simular um estado desejado, por exemplo, de riqueza, desvinculado do valor real do objeto. As pessoas consomem freneticamente para experienciar as emoções ocasionadas por esse estado de ilusão que se ausenta da consciência e, como a sensação é de uma satisfação provisória, procuram sempre mais, retroalimentando a própria hiper-realidade.

Uma das tarefas da educação, ou da instituição escola, seria convidar os jovens a olhar atrás dos aparatos para que vissem o que não veem. $\mathrm{O}$ homem associou trabalho e consumo em uma mesma categoria. Assim, para consumir, é preciso trabalhar, que se opõe ao lazer, entendido, desta forma, como algo não necessário; somente o trabalho é uma atividade séria e produtiva, capaz de produzir riqueza para consumir.

Confúcio afirmava que é preciso arrumar um trabalho de que se goste, porque assim nunca mais será preciso trabalhar. Associar trabalho e lazer passa a ser uma tarefa da educação, pois o trabalho não deve ser visto como uma forma de alienação, e sim de emancipação. O produto final do trabalho não pode ser o consumo exacerbado da inutilidade imposta pelo mercado, mas o prazer da criação. Isso não significa que o trabalho deva ser fácil, pois dificilmente pode empolgar aqueles que, apesar dos grandes esforços despendidos e sem nenhuma recompensa salarial, queiram fazê-lo pelo prazer, a exemplo do xadrez, que se caracteriza como um trabalho altamente especializado e sem valor de troca.

As pessoas imersas na hiper-realidade e despojadas de qualquer crítica poderiam ter imprimido em seus corpos um código de barras para quantificar o quanto valem por se submeterem a ser vitrines vivas, expondo signos que simulam o nada.

Interagir nessa realidade é semelhante a intervir nos sonhos, como se de alguma maneira o personagem pudesse mudar ou conduzir os destinos do roteiro no cenário dos sonhos. Entretanto, como tudo na hiper-realidade somente parece ser, a interação também é fictícia, 
O modelo de escola que temos prepara os jovens para viverem na sociedade atual?

R. Museu Arq. Etn., 32: 41-48, 2019.

porque o cenário e as pessoas não estão situados no real. Foram propositadamente programados para gerar mais ilusão na ilusão. Novamente, essa interação gera uma falsa sensação de felicidade que precisa se perpetuar, forçando a continuidade do processo indefinidamente.

O olho humano pode ser um grande traiçoeiro. Aquilo que o homem vê nem sempre é o que parece ser. Narciso foi condenado por uma ninfa a jamais alcançar o objeto de sua paixão. Quando viu pela primeira vez sua imagem refletida nas águas de um lago, apaixonou-se perdidamente. A imagem não era absolutamente nada a não ser ele mesmo. Se Narciso tivesse percebido que o objeto de sua paixão era ele mesmo e não sua imagem, provavelmente teria conseguido burlar a maldição, visto que viver apaixonado por si mesmo não é causa de maiores desconfortos. Pode até ser considerado uma virtude gostar de si e usufruir intensamente da sua própria companhia. Afinal, a solidão pode ser somente a ausência de si.

Baudrillard afirma que "dissimular é fingir não ter o que se tem e simular é fingir ter o que não se tem" (Baudrillard 1991:9). Toda a hiper-realidade simula o que não se tem e, com esta simulação, é capaz de articular inúmeros esquemas de manipulação. $\mathrm{O}$ capital é um bom exemplo dessa afirmação. "O capital imoral e sem escrúpulos só pode exercer-se por detrás de uma superestrutura moral, e quem quer que seja que regenere esta moralidade pública pela indignação ou pela denúncia, trabalha espontaneamente para a ordem do capital" (Baudrillard 1991:23). Desta maneira, torna-se muito difícil escapar das artimanhas dessa lógica.

Descobrir onde está a verdade em tudo isso e quais os verdadeiros mecanismos de manipulação é uma tarefa impossível, mesmo porque nem seus autores sabem mais onde se iniciou a verdade ou a simulação. Para Baudrillard, a ilusão não é mais possível porque já não existe o real. Assim, todas as forças devem estar concentradas no resgate do real, apesar de não ser mais possível prová-lo.

Embora possa parecer ingenuidade, viver e conviver nessa hiper-realidade na qual não se pode mais achar o real, de forma menos ilusória seja possível por meio de um questionamento perene sobre os fatos, individual e coletivamen- te, sempre duvidando de suas próprias ideias, as quais podem ser a origem da manipulação, para ao menos perceber a existência de simulações criadoras de verdadeiros fantoches que imaginam ter vida própria.

Outra possibilidade seria resgatar o conceito de parresia dos gregos e aclamado por Foucault, "O governo de si e dos outros" definido como práticas do dizer a verdade sobre si mesmo, o antídoto contra a hipocrisia, o fingimento e a mentira. $\mathrm{O}$ exercício da parresia exige muita coragem, pois ver-se, desnudar-se, virar-se do avesso poderá ser o encontro com fantasmas que estavam confortavelmente escondidos. Ao enxergar-se, como imagem refletida, vê-se melhor o outro sem os vários véus que encobrem, propositadamente, a simulação e a dissimulação.

Cultivar o estranhamento como o ato de estranhar o que está posto e pronto, de incomodar-se, de não se acomodar, de resistir pode ser uma outra forma de enfrentar a hiper-realidade, contida na cultura global. Do estranhamento advém a desnaturalização, ou seja, o não aceitamento daquilo que é considerado "natural", pois o mundo do humano é cultural, uma vez que, a sua natureza é ser cultural. Desta maneira, a suposta realidade pode ser transformada, não sendo inflexível nem imutável.

Deleuze fala em "zonas de escape". Uma metáfora para exemplificar isso seria a membrana semipermeável das células. Ela as envolve e controla o que deve entrar e sair pelos microporos. Entretanto, há momentos em que acontecem movimentos de entrada e saída da célula, livres de controle e sem gasto de energia. Evidentemente, após determinada quantidade de moléculas movimentadas por esse transporte passivo, a célula volta a exercer o controle para a própria sobrevivência. Assim, as zonas de escape seriam como os microporos das membranas plasmáticas das células.

Se vemos somente a simulação do mundo real, e não vemos que não vemos, não seria a simulação a única prova de que estivemos no mundo? Para procurar responder a essa questão, é fundamental saber que a percepção é limitada, e até seria possível afirmar que cada um de nós tem um mundo privado. "Tais mundos não são mundos a não ser para seu titular, eles não são 
o mundo" (Merleau-Ponty 2007: 21). Então, como acessar o mundo se o outro, que poderia ver o que não vejo, possui as mesmas limitações? Talvez "essa certeza injustificável de um mundo sensível comum a todos nós é, em nós, o ponto de apoio da verdade" e "a nossa segurança de estar na verdade e estar no mundo é uma só" (Merleau-Ponty 2007: 23).

O desafio da educação contemporânea é suscitar um apelo a uma autorreflexividade perante esse bombardeio de imagens e falsidades e favorecer que o humano volte a se encantar com a simplicidade, concomitantemente com a complexidade da própria existência, que consiga potencializar o ser e o fazer humano e, ainda, favorecer que o jovem seja capaz de perceber o belo que inunda o mundo.

Assim, à educação caberia desvendar o erro, a ilusão e possibilitar lampejos de esperança freiriana, capazes de concretizar o sonho das pequenas utopias que se contrapõem à percepção da total ausência de sentido, onde todos, incessantemente e equivocadamente, procuram sentidos para justificar a existência

Infelizmente, a escola atual, caso não se permita uma profunda inflexão sobre si mesma, poderá contribuir para a perpetuação de uma cristalização e imobilidade confortáveis, que reforçará a alienação e a desesperança.

\section{Escola como uma grande comunidade virtual de aprendizagem}

As comunidades virtuais apresentam como uma de suas principais características a autopoiese, a capacidade de autoprodução, auto-organização e autogerenciamento, podendo-se imaginar que um sistema autopoiético é ao mesmo tempo produtor e produto e, de forma paradoxal, é um sistema autônomo e dependente. Entretanto, essa dependência é uma interdependência entre os integrantes da própria comunidade, estabelecendo-se uma relação complexa e mutável.

Outra característica da comunidade virtual é o nomadismo caracterizado pelo enraizamento dinâmico, a não fixação do espaço, o desejo de outro lugar e a circularidade em oposição à linearidade da era moderna. Essa errância aponta para o desejo de religar todos a tudo, como pontes líquidas que se entremeiam por todos os espaços, conectando, hibridando e miscigenando o existente. Assim, as relações nas comunidades virtuais são autoprodutoras e produto da subjetividade volátil e mutável de seus integrantes.

"O que estará daqui em diante na ordem do dia é o resgate de campos de virtualidade futuristas e construtivistas. O consciente permanece agarrado em fixações arcaicas apenas enquanto nenhum engajamento o faz projetar-se para o futuro. Essa tensão existencial operar-se-á por intermédio de poralidades humanas e não humanas. Entendo por estas últimas o lineamento ou, se quisermos, o obramento de devires maquínicos, correlativos da aceleração das revoluções tecnológicas e formáticas (é assim que vemos desenvolver-se a olhos vistos a expansão prodigiosa de uma objetividade assistida por computador)" (Guattari 1990:21).

O ambiente virtual, em geral, é flexível, fluido, mutável, híbrido, instável, dinâmico, complexo e diferenciado. Pode favorecer o aprender, o ensinar, o conviver, o transformar das relações humanas, o harmonizar do local e do global, o fomentar das relações de interdependência e o privilegiar da ecosofia, definida como "uma articulação ético-política entre os três registros ecológicos: o do meio ambiente, o das relações sociais e o da subjetividade humana. O que está em questão é a maneira de viver daqui em diante sobre este planeta, no contexto da aceleração das mutações técnico-científicas e do considerável crescimento demográfico. Em função do contínuo desenvolvimento do trabalho maquínico redobrado pela revolução informática, as forças produtivas vão tornar disponível uma quantidade cada vez maior do tempo de atividade humana potencial. Mas com que finalidade? A do desemprego, da marginalidade opressiva, da solidão, da ociosidade, da angústia, da neurose, ou da cultura, da criação, da pesquisa, da reinvenção do meio ambiente, do enriquecimento dos modos de vida e da sensibilidade?" (Guattari 1990:9).

A ecosofia como registro ecológico de uma articulação ético-política pode ser vista como 
O modelo de escola que temos prepara os jovens para viverem na sociedade atual?

R. Museu Arq. Etn., 32: 41-48, 2019.

uma solução dentro de uma visão "holo" e específica na sociedade contemporânea, na qual o homem é um habitante do virtualizado, que poderá ser considerado uma metrópole comunicacional repleta de conflitos, capaz de autotransformar esse ambiente e alterar as relações de produção e distribuição dos meios convencionais. É, ainda, um espaço plurilógico, no qual se cruzam as interioridades, as emoções, tornando a comunicação ex-terminável, no sentido de jamais estar terminada e sempre em construção, produzindo-se e reproduzindo as identidades provisórias dos participantes, propiciando a transvaloração de todos.

O espaço virtual pode ser considerado uma interzona, um fragmento com autonomia, um local de produção, alienação e prazer que poderá transformar a subjetividade, construir um presente com elementos ainda não descobertos, não experimentados. Um local de inventar o novo, novas formas de vida, que assume outra configuração e outro sentido, no qual cada um possui uma representatividade e uma única forma de registro.

$\mathrm{O}$ virtual é a possibilidade de vir a ser. $\mathrm{O}$ homem no ambiente digital passa a ser também uma possibilidade de vir a ser, de vir a se construir, a se reconstruir e a se ressignificar por meio do desenvolvimento de novas habilidades e competências e da atribuição de novos significados à sua existência. As mudanças no ambiente virtual são mais rápidas, desencadeando a formação de novas identidades provisórias individuais e coletivas, que poderão ter reflexo nas relações presenciais.

O virtual, que representa a possibilidade de ser, aumenta o que já é multiplicado. Assim, há a possibilidade de ser efetivamente vários, de assumir várias identidades, de fazer vários relacionamentos e interações, construir várias realidades e aumentar o nível de abrangência da consciência. Significa ver através do outro, existir através dos seus múltiplos agregados aos múltiplos do outro e, assim, minimizar o fato de não vermos que não vemos.

Para Deleuze, "o rizoma tem como tecido a conjunção 'e... e... e...' Há nesta conjunção força suficiente para sacudir e desenraizar o verbo ser" (Deleuze 1995:37). A transgressão do modelo de árvore para o de rizoma poderá ser facilitada e potencializada por meio dos ambientes digitais. $\mathrm{O}$ modelo árvore é linear, com um começo-raiz, meio-tronco e fim-folhagens, sendo que as ramificações são relativamente ordenadas, seguindo um padrão; é temporal, limitado em um espaço circunscrito e finito. O rizoma, um tipo de caule subterrâneo, não é linear, não há começo, meio nem fim; é simplesmente o todo, com inúmeras ramificações, sem padrão definido; é atemporal, o espaço não é o entorno e, assim, como o bulbo e o tubérculo, pode permanecer vivo em situações bastante adversas, como em um tipo de encistamento. $\mathrm{O}$ rizoma tem formas muito diversas, representa o potencial, o vir a ser, mas já existe, assim como o virtual. Quando as condições desfavoráveis mudam, ele se transforma, é mutável, flexível, capaz de se renovar, é a possibilidade de multiplicidade.

O virtual que segue o modelo de rizoma pode ser um território singular, através da criação, da reinvenção, da transformação do ambiente, do enriquecimento dos modos de manifestação da vida e da sensibilidade, ou pode se tornar, cruelmente, um espaço de desterritorialização, através do desemprego, da marginalidade opressiva, da solidão, da ociosidade, da angústia, da neurose.

A desordem aparente dos ambientes digitais que se configuram polissêmicos e polifônicos é o fluxo que está por vir, é a fonte de toda a mudança e, consequentemente, de toda a vida e de toda a humanicidade, é a inauguração da antropologia do ciberespaço.

A tecnologia age somente como catalisador da pré-disposição interna dos participantes dos ambientes digitais, como potencializadora da complexidade do humano, para aqueles que almejam as pequenas utopias que nos fazem caminhar para e com o outro. Essa mesma tecnologia permite que os dizeres midiatizados fiquem registrados e levem a recuperação da memória a níveis jamais alcançados.

Enfim, o virtual é um ambiente de produção de cultura e conhecimento e, assim, de um ambiente de produção de humanidade. Para aqueles que possuem ou divulgam uma visão pessimista sobre o futuro do humano pelo uso das novas tecnologias e pela vivência em ambientes virtuais, é preciso lembrar que, durante 
o processo de evolução do ser humano, sempre houve perdas que acarretaram novos ganhos. O perder ou a mudança de algo foi a causa da aquisição de uma nova possibilidade de existir. Quando o homem se transformou de quadrúpede em bípede, a mão ficou livre para pegar e manusear os objetos, o que acarretou uma mudança significativa na história de sua evolução.

Assim, o pós-humano ou o homem fisicamente atrelado de forma indissociável à tecnologia pode ser o inaugurar de uma nova era do mesmo humano, que dificilmente poderá ser valorada como melhor ou pior, somente diferente. Talvez um humano capaz de viver em condições ambientais futuras adversas neste planeta, criadas pelo próprio homem, nas quais o homem atual não estaria adaptado para sobreviver. Nesse pensar, a tecnologia estaria somente garantindo a sobrevivência do humano.

O que fará o diferencial será aquilo que porta o pior perigo, mas que também traz as melhores esperanças: o próprio humano. Daí advém a grande importância da reforma do pensamento, do prazer de ser uma mente ativa, da formação de educadores criativos e que tenham competência suficiente para transformar uma tecnologia que eventualmente tenha sido gerada e pensada para fins de controle e dominação em instrumento de emancipação e valorização da genuína cultura regional e global.

ALVES, A. C. T. P. Does the school model we have prepare young people to live in today's society? R. Museu Arq. Etn., 32: 41-48, 2019.

Abstract: Postmodern society, post-industrial society, liquid modernity, posthuman, hypersphere, artificial intelligence, Web 3.0, industry 4.0, society of fatigue, setting on Mars. In the midst of this social upheaval, it is urgent to reflect on the role of the school institution today. Does it fulfill its main function, i.e. to prepare the young people inclusion in the work environment and to develop a social conscience? How can we help future generations to face the enormous challenges that will arise in a social model that we do not know yet, in a world where uncertainty is the only certainty, where everything solid was liquefied? Is the integration of Digital Information and Communication Technologies - ICT in curricula sufficient for the school to solve the immeasurable problems that it faces? Morin states that "men always construct false conceptions of themselves, of what they do, of what they must do, of the world in which they live." In this way, it would be up to the school to unveil the illusion and have the courage to practice the parrhesia of the Greeks, which means having the courage to tell the truth about oneself. The school must have the courage to see itself, realizing its fragilities. The tree model, sequential, linear, imposed throughout time no longer contemplates a rhizomatic society, in which there is the multiplicity of multiples. The world will never be the same after the advent of ICT. Artificial intelligence and the symbiotic relationship between man and machine will radically change the way humans are, be and perceive the world. There will be no way for man to compete with the machine. In this way, it will not be for the school to train technocrats for the world environment, but to rescue what the human has the best, which is their subjectivity, their capacity to feel, their singularity, their unicity in the midst of multiplicity.

Keywords: Global culture; Hypersphere; Virtual communities; Digital technologies; School. 


\section{Referências bibliográficas}

Baudrillard, J. 1991. Simulacros e simulação. Relógios d'Água, Lisboa.

Bauman, Z. 2008. Medo líquido. Jorge Zahar, Rio de Janeiro.

Benjamin, W. 1994. Magia e técnica, arte e política: ensaios sobre literatura e história da cultura. 7. ed. Brasiliense, São Paulo.

Bergson, H. 2006. Memória e vida. Martins Fontes, São Paulo.

Confúcio. 2007. Os analectos. L\&PM, Porto Alegre.

Deleuze, G.; Guattari, F. 1995. Mil platôs - capitalismo e esquizofrenia. Editora 34, Rio de Janeiro, v. 1, 2 e 3.
Foucault, M. 1999. As palauras e as coisas. 8. ed. Martins Fontes, São Paulo.

Guattari, F. 1990. As três ecologias. Papirus, Campinas.

Merleau-Ponty, M. 2002. A prosa do mundo. Cosac \& Naify, São Paulo.

Merleau-Ponty, M. 2007. O visível e o invisível. São Paulo: Perspectiva.

Morin, E. 2000. Os sete saberes necessários à educação do futuro. Unesco; Cortez.

Schopenhauer, A. 2003. Metafísica do belo. Editora da Unesp, São Paulo. 